\title{
Seismic Response of Two Engineering-Geological Sites of the Kanevskaya Pumped Storage Power Plant Territory
}

\author{
Semenova Yuliia
}

Department of Science, Subbotin Institute of Geophysics of the National Academy of Sciences of Ukraine, Kiev, Ukraine

\section{ABSTRACT}

Article Info

Volume 8, Issue 3

Page Number : 232-237

\section{Publication Issue}

May-June-2021

\section{Article History}

Accepted : 14 May 2021

Published : 22 May 2021
The article examines the influence of the peculiarities of local soil conditions on the manifestations of earthquakes on the free surface on the example of the territory of the Kanevskaya pumped storage power plant. The study area was divided into 2 engineering-geological sites with the expected different seismic effect. A comparison is made of the frequency characteristics of the soil of both plots and the maximum values of the amplitude Fourier spectra on the free surface, obtained as envelopes of the Fourier spectra calculated for 26 input seismic motions. The change with the depth of peak shear strain in soil sections of both sites is also considered.

Keywords : Fourier Spectra, Seismic Motion, Science, Earthquake, Seismic Microzoning

\section{INTRODUCTION}

In terms of their destructive consequences, the number of victims and huge material losses, earthquakes occupy one of the first places among other natural disasters. According to UNESCO, only in the last century, an average of about 10 thousand people died from earthquakes every year. The losses from direct earthquake damage and indirect material losses caused by these earthquakes during this period are estimated at an astronomical figure approaching 100 billion US dollars. It is impossible to prevent earthquakes, but their destructive consequences can be reduced or prevented by creating reliable seismic zoning maps, constructing calculated accelerograms that simulate future vibrations at construction sites, applying adequate seismic-resistant construction standards and the ability to withstand seismic effects.

The relevance of research on the topic is due to the fact that the solution to the problem of seismic protection is possible only on the basis of a reliable establishment of the patterns of manifestation of seismic vibrations from close and strong distant earthquakes at specific construction (operational) sites [2]. International experience shows that it is easier and cheaper to prevent the adverse consequences of natural disasters than to eliminate their catastrophic consequences later. Losses from earthquakes can be significantly reduced with proper technical and organizational preparation for them. To ensure the stable development of territories, central and local authorities, organizations conducting geophysical 
research, design and construction, need to have data on modern geodynamic activity, as well as scientifically substantiated predicted values of parameters that quantitatively describe the real danger from these processes.

Examples of devastating earthquakes (Spitak (1988); Loma Prieta (1989); Northridge (1994); Kobe (1995); Neftegorsk (1995); Taiwan (1999, 2018); Gujarat (2001), China (2008, 2010, 2013, 2014) of recent decades show that damage to buildings and structures on different soil conditions varies significantly. Strong and, at first glance, "earthquake-resistant" structures are often destroyed, while less strong low-rise buildings remain intact. The frequency composition and duration of ground vibrations directly effect on the energy supplied to the structure and causing damage to its elements.

\section{METHODS AND MATERIAL}

Modelling the response of the soil to the input seismic motions a classic problem of engineering seismology, that is, the problem of the propagation of a seismic wave falling vertically from below from elastic to half-space, in the thickness of the overlying layers. The reaction of the soil should be calculated taking into account all the mechanisms of transformation of seismic waves in soils, including the nonlinear response.

This problem was first theoretically solved by Kanai [1] for a system of sedimentary layers characterized by Kelvin-Voight viscous elasticity; it was shown that the motion of a point on the surface of the sedimentary strata is mainly determined by shear waves propagating vertically upward from the bedrock [1]. On this basis, based on the theory of multiple reflected waves, various procedures have been developed for calculating the vibrations of the surface of the sedimentary strata from the vibrations of the bedrock or adjacent rock outcrops.

Initial data, depending on the conditions of the problem, can be presented in the form of amplitude and phase frequency characteristics of a given soil model; oscillograms (accelerograms, velocigrams, seismograms) on the free surface, or at internal points of the medium, the response spectrum of the corresponding calculated accelerogram, Fourier functions, and the like.

When modelling the response of the soil to seismic movement within the framework of the theory of propagation of seismic waves, a crucial step is to represent the cyclic work of the soil in the form of a material model that establishes the relationship between shear stresses and shear deformation. Modelling the work of the soil under cyclic loads makes it possible to obtain deformation characteristics in the considered range of strain. At different times, simple rational models were created that characterized the most important aspects of the behaviour of soils: linear-elastic, viscous-elastic, nonlinear-elastic, elastic-plastic, etc. models [4].

Currently, in the world practice of engineering seismology, three classes of models of soil behaviour are used: linear, equivalent linear and nonlinear models. All these models are based on stress-strain relationships, which describe both general patterns of soil behaviour and their nonlinear properties.

An equivalent linear model based on the concept of viscous circle was used as an analytical tool. It is assumed that all displacements are caused by shear waves that propagate vertically upward from a halfspace, then all displacements are horizontal and within each layer of the soil strata satisfy the wave equation:

$$
\rho \frac{\partial^{2} u}{\partial t^{2}}=G \frac{\partial^{2} u}{\partial z^{2}}+\eta \frac{\partial^{3} u}{\partial z^{2} \partial t}
$$

where $\mathrm{u}=\mathrm{u}(\mathrm{t}, \mathrm{z})$ is horizontal displacement, $\mathrm{t}$ - is time, $G$ is shear modulus, $\eta$ is viscosity, $\rho$ is density.

The amplitude of harmonic oscillations with frequency $\omega$ is presented in the form:

$$
u(z, t)=U(z) e^{i \omega t}
$$

Then the general solution of the wave equation (1) will be: 


$$
U(z)=A e^{i k z}+B e^{-i k z}
$$

where $\mathrm{A}$ and $\mathrm{B}$ are the amplitudes of waves propagating up and down along the $\mathrm{Z}$ axis;

$\mathrm{k}$ - complex wavenumber:

$$
k^{2}=\frac{\rho \omega^{2}}{G+i \omega \eta}=\frac{\rho \omega^{2}}{G^{*}}
$$

where $\eta$ is the viscosity, $G$ is the shear modulus, $G^{*}$ is the complex shear modulus, which can be calculated using one of the formulas (5-7):

$$
\begin{gathered}
G^{*}=G\left(1-2 \xi^{2}+i 2 \xi \sqrt{1-\xi^{2}}\right) \\
G^{*}=G\left(1-\xi^{2}+i 2 \xi\right) \\
G^{*}=G(1-i 2 \xi)
\end{gathered}
$$

In this work, we used the formula (6).

The amplitudes A and B vary from layer to layer and are related by formulas $(8$ - 9), arising from the conditions of continuity of stresses and displacements at the boundaries of the layers.

$$
\begin{aligned}
& A_{j+1}+B_{j+1}=A_{j} e^{i k_{j} h_{j}}+B_{j} e^{-i k_{j} h_{j}} \\
& A_{j+1}-B_{j+1}=\alpha\left(A_{j} e^{i k_{j} h_{j}}+B_{j} e^{-i k_{j} h_{j}}\right)
\end{aligned}
$$$$
\text { Where } \alpha_{j}=k_{j} G_{j}^{*} / k_{j+1} G_{j+1}^{*}
$$

Whence can be obtained recurrent formulas for the displacement amplitudes $A j+1, B j+1$ in layer $j+1$ through the amplitudes in layer $\mathrm{j}$ :

$$
\begin{gathered}
A_{j+1}=\frac{1}{2} A_{j}\left(1+\alpha_{j}\right) e^{i k_{j} h_{j}}+\frac{1}{2} B_{j}\left(1-\alpha_{j}\right) e^{-i k_{j} h_{j}} \\
B_{j+1}=\frac{1}{2} A_{j}\left(1-\alpha_{j}\right) e^{i k_{j} h_{j}}+\frac{1}{2} B_{j}\left(1+\alpha_{j}\right) e^{-i k_{j} h_{j}}
\end{gathered}
$$

or

$$
\left\{\begin{array}{l}
A_{j+1} \\
B_{j+1}
\end{array}\right\}=\left[\begin{array}{ll}
\left(1+\alpha_{j}\right) e^{i k_{j} h_{j}} & \left(1-\alpha_{j}\right) e^{-i k_{j} h_{j}} \\
\left(1-\alpha_{j}\right) e^{i k_{j} h_{j}} & \left(1+\alpha_{j}\right) e^{-i k_{j} h_{j}}
\end{array}\right]\left\{\begin{array}{l}
A_{j} \\
B_{j}
\end{array}\right\}
$$

Considering that the stresses on the free surface are equal to zero, we obtain $\mathrm{A} 1=\mathrm{B} 1$, that is, the amplitudes of the incident and reflected waves are always equal on the free surface.
Wave amplitudes (A and B) within the soil model are calculated at each frequency (assuming known severity and absorption within each layer) and used to calculate the surface response.

Applying the recurrent formulas (10) and (11) sequentially to all layers from 1 to $j$, it is possible to express the wave amplitudes in all layers through A1 and B1. The frequency response, which connects the displacement amplitudes in the $\mathrm{i}$-th and $\mathrm{j}$-th layers, has the form:

$$
H_{i j}(\omega)=\frac{\left|u_{i}(\omega)\right|}{\left|u_{j}(\omega)\right|}=\frac{a_{i}(\omega)+b_{i}(\omega)}{a_{j}(\omega)+b_{j}(\omega)}
$$

The frequency response of a multi-layer soil strata is complex, but it is calculated in the same way as in the case of a single layer in a half-space. For the computer program PROSHAKE $[5,7]$ was used.

The speed $\dot{u}(z, t)$ and acceleration $\ddot{u}(z, t)$ associated with displacement are as follows:

$$
\begin{array}{r}
\dot{u}(z, t)=\frac{\partial u}{\partial t}=i \omega u(z, t) \\
\ddot{u}(z, t)=\frac{\partial^{2} u}{\partial t^{2}}=-\omega^{2} u(z, t)
\end{array}
$$

Therefore, the equation of the frequency response (13) describes the amplification of oscillations also for accelerations and velocities from layer $i$ to $j$.

Fourier amplitude spectrum on the surface is calculated by multiplying the Fourier amplitude spectrum of the input motion in half space by the frequency response of the soil:

$$
Y_{i}(\omega)=H_{i j}(\omega) Y_{j}(\omega)
$$

where $Y_{i}(\omega)$ is the Fourier amplitude spectrum on the surface, ${ }_{j}(\omega)$ is the Fourier amplitude spectrum of the input signal in the half-space, ${ }_{i j}(\omega)$ is the frequency response of the layered soil mass.

Shear strain at depth $\mathrm{z}$ at time $\mathrm{t}$ can be obtained from the wave equation as: $\gamma(z, t)=\frac{\partial u}{\partial z}=i k\left(A e^{i k z}-B e^{-i k z}\right) e^{i w t}$ 
The corresponding shear stress at depth $\mathrm{z}$ and at time t will be: $\tau(z, t)=G^{*} \gamma(z, t)$.

The nonlinear behavior of soils and, accordingly, the change in the parameters $G$ and $D$, depending on the shear deformation $\gamma$, in the equivalent linear modeling are taken into account by iterating until a satisfactory solution is obtained [4].

The iterations are carried out as follows:

1. For each layer, the initial values are initialized $G_{i}$ and $D_{i}$ at small values of the shear deformation.

2. The displacement of the soil and, accordingly, the maximum amplitudes $\gamma$ in each layer are calculated.

3. Using the maximum value of $\gamma$, the effective shear strain ${ }^{\gamma_{\text {eff }}}$ in each layer is calculated: $\gamma_{\text {eff }}{ }^{i}=R_{\gamma} \gamma_{\text {max }}^{i}$, where the superscript denotes the iteration number $R_{\gamma}$ - depends on the magnitude $\mathrm{M}$ of the earthquake and is taken as the same value for all layers of the soil model and is calculated by the formula: $R_{\gamma}=(M-1) / 10$.

4. Based on the calculated $\gamma_{\text {eff }}$, new parameters $G^{(i+1)}$ and $D^{(i+1)}$ are selected for the next iteration.

5. Steps $2-4$ are repeated until the difference between the calculated values of the shear modulus and the absorption coefficient in two successive iterations becomes less than a certain predetermined value for all layers. Usually 3 - 5 iterations are enough to achieve a difference of less $(5-10) \%$ [4].

Iterative calculations ensure that the parameters $G$ and $\mathrm{D}$ correspond to the levels of deformations $\gamma$ in all layers of the soil strata.

\section{SEISMIC RESPONSE OF THE SOIL IN THE TERRITORY OF THE LOCATION OF THE MAIN STRUCTURES OF THE KANEVSKAYA HPP}

During the seismic microzoning, 2 engineeringgeological sites No. 1 and No. 2 were allocated within the territory of the territory for the location of the main structures of the Kanevskaya HPP. For engineering-geological sites No. 1 and No. 2, averaged models of the geological environment were built.

To assess the influence of the sedimentary strata, onedimensional (horizontally layered models of the environment) were used, which is quite acceptable in conditions near the horizontal occurrence of the main geological elements of the sedimentary strata.

The analysis of the seismic response of models of soil strata of the territory of the location of the main structures of the Kanevskaya HPP was carried out using an equivalent-linear model and the ProShake software [5, 7].

The figure 1 shows the calculated frequency characteristics of soils for the engineering-geological sections No. 1 and No. 2 of the territory of the Kanevskaya HPP.

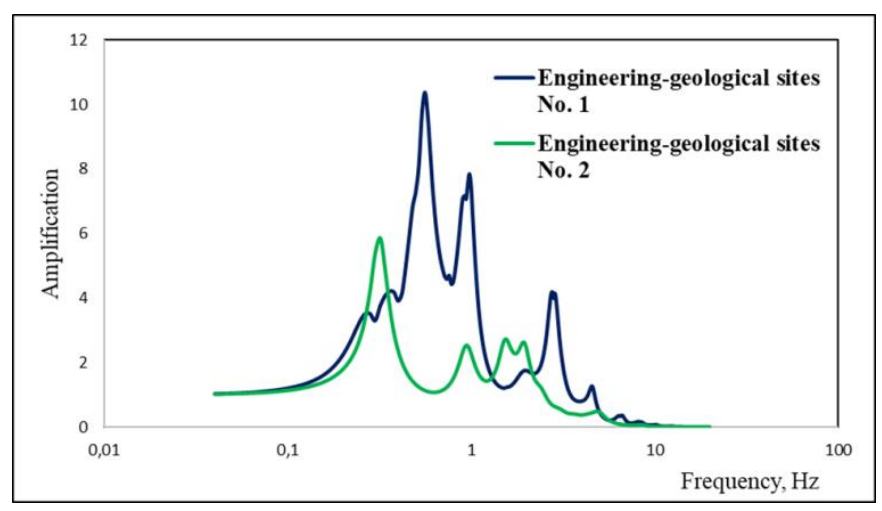

Figure 1: Frequency characteristics of soils for the engineering-geological sections No. 1 and No. 2 of the territory of the Kanevskaya HPP

The frequency response of the engineering-geological site No. 1 is characterized by the frequency range of resonant amplification of vibrations by local ground conditions from 0.26 to $3.02 \mathrm{~Hz}$. The greatest amplification of vibrations by local soil conditions of 
the investigated area can be observed in the frequency range from 0.44 to $1.06 \mathrm{~Hz}$ with a seismic vibration amplification factor of 10.37 .

The frequency response of the engineering-geological site No. 2 is characterized by the frequency range of resonant amplification of vibrations by local ground conditions from 0.22 to $2.08 \mathrm{~Hz}$. The greatest amplification of vibrations by local soil conditions of the investigated area can be observed in the frequency range from 0.26 to $0.38 \mathrm{~Hz}$ with a seismic oscillations amplification factor of 5.86 .

Figure 2 shows the amplitude Fourier spectra of ground vibrations on the surface of two engineeringgeological regions of the Kanevskaya HPP territory, calculated from the maximum values of the Fourier spectra on the surface of 26 input seismic movements with different amplitudes and spectral composition.

The Fourier amplitude spectrum is one of the most important parameters of the ground surface oscillations during earthquakes and is widely used in assessing seismic hazards and for predicting the characteristics of strong motions.

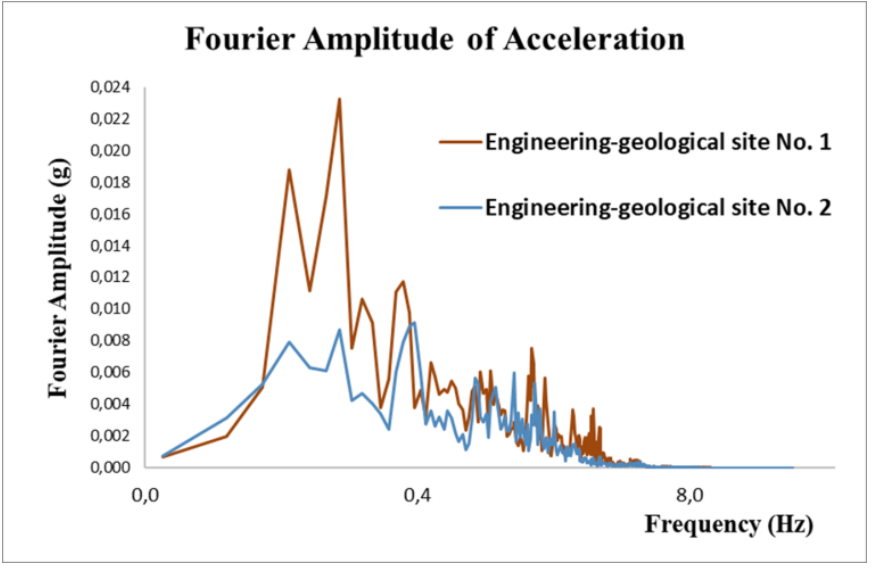

Figure 2: Maximum amplitude Fourier spectra of ground vibrations on the surface of engineeringgeological regions No. 1 and No. 2 of the territory of Kanevskaya HPP

The Fourier amplitude spectra presented in Fig. 2 demonstrate the difference in the manifestation of earthquakes on the free surface of two engineeringgeological sites within the territory of the Kanevskaya HPP. The maximum amplitude values of the Fourier spectrum of soil vibrations on the surface of the engineering-geological site No. 1 are $0.023 \mathrm{~g}$, which is 2.5 times higher than the values of the engineeringgeological site No. 2. Thus, it can be argued that the engineering-geological region No. 1 is more dangerous in terms of seismicity in comparison with the engineering-geological site No. 2.

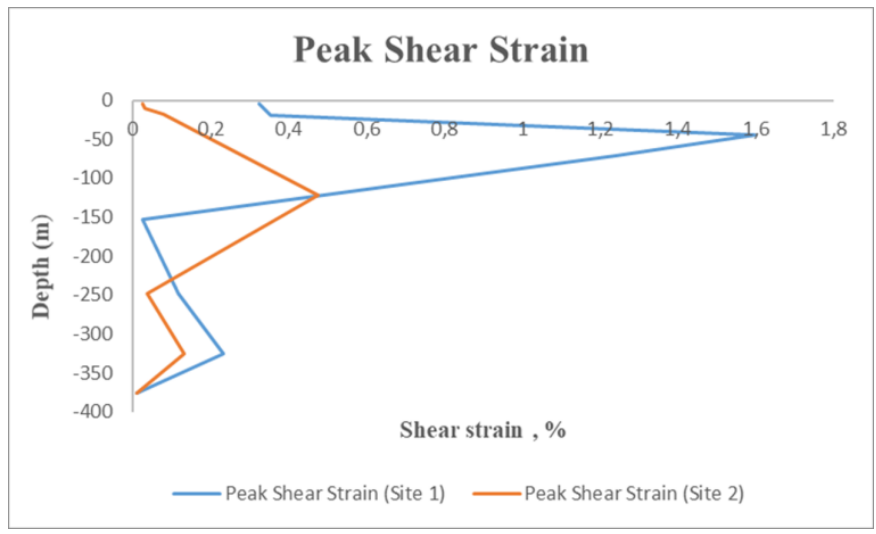

Figure 3: Graphs of changes in peak shear strain with depth in soil sections of engineering-geological sites No. 1 and No. 2 of the territory of Kanevskaya HPP

Fig. 3, it can be seen that high values of peak shear strain are observed in the soil section of the engineering-geological site No. 1, which rapidly began to grow from a depth of $150 \mathrm{~m}$ and acquired maximum values at a depth of $44 \mathrm{~m}$. This phenomenon can be explained by the fact that in the model of the soil section of the engineering-geological site No. 1 there is a sharp boundary of acoustic stiffness between the layers, which caused an increase in the amplitude of the seismic wave and, accordingly, the strain of the "weak" layer. The model of the soil section of the engineering-geological site No. 1 from the bedrock to the free surface is characterized by a smoother decrease in the values of the shear wave velocity and the density of the soil layers.

\section{IV.CONCLUSION}

The nature and distribution of earthquake damage is largely determined by the response of local soil conditions to seismic impact. The destructive effect is 
determined by the spectral composition and intensity of seismic vibrations. Under strong seismic impacts, the behaviour of soils becomes nonlinear and the problem of assessing the response of the soil becomes much more complicated. Under such conditions, the response of the soil depends both on the composition, physical parameters, thickness and water saturation of the soil layers, and on the intensity of the earthquake and the frequency composition of oscillations in its source and on the roof of the consolidated foundation under the site. During intense earthquakes, compaction and subsidence, loosening and swelling of loose soils can be observed, and in some cases, liquefaction of water-saturated soils and other dangerous phenomena. The nonlinearity of the soil reaction leads to a significant change in the shape and spectrum of seismic vibrations propagating in the soil layers. Resonant frequencies, at which amplification of ground vibrations are observed in this case, turn out to be dependent on the intensity of seismic effects. The results presented in the work demonstrate that in order to ensure the seismic resistance of structures, it is necessary to analyse the seismic response for each area. The variety of soil conditions and the laws of propagation of seismic waves in them require a detailed study of the properties of each site and the calculation of accelerograms, taking into account the properties of local soils.

\section{REFERENCES}

[1]. Kanai K., 1952. Relation between the nature of surface layer and the amplitudes of earthquake motions. Bull. Earth. Res. Inst., Tokyo Univ. 30, 31-37.

[2]. Kendzera O., Rushchitsky J., Semenova Y. (2021) Rheological Properties of Soils in Assessing the Seismic Hazard of the South Ukrainian Nuclear Power Plant. In: Bonali F.L., Pasquaré Mariotto F., Tsereteli N. (eds) Building Knowledge for Geohazard Assessment and Management in the Caucasus and other
Orogenic Regions. NATO Science for Peace and Security Series C: Environmental Security. Springer, Dordrecht - P. 365-373 https://doi.org/10.1007/978-94-024-2046-3_20

[3]. Kendzera O., Semenova Y. Seismic zoning of Kyiv in physical parameters of soil oscillations // Geodynamics. 2020; Volume 2 (29) 2020, Number 2(29): 97-106 https://doi.org/10.23939/jgd2020.02.097

[4]. Kramer S. L., 1996. Geotechnical Earthquake Engineering. N. J.: Prentice Hall, Upper Saddle River, 672 p.

[5]. ProShake Ground Response Analysis Program, version 1.1. User's Manual, EduPro Civil Systems, Washington, USA, 1998, 54 p.

[6]. Udaka, T. (1975) " Analysis of Response of Large Embankments to Travelling Base Motions", Ph.D. Dissertation, University of California, Berkeley, December.

[7]. Schnabel P. B., Lysmer J., Seed H. B., 1972. SHAKE: A computer pro-gram for earthquake response analysis of horizontally layered sites. Report No. EERC 72-12. Berkeley, California: Earthquake Engineering Research Center, University of California, 102 p.

\section{Cite this Article}

Yuliya Semenova, "Seismic Response of Two Engineering-Geological Sites of the Kanevskaya Pumped Storage Power Plant Territory", International Journal of Scientific Research in Science and Technology (IJSRST), Online ISSN : 2395-602X, Print ISSN : 2395-6011, Volume 8 Issue 3, pp. 232-237, May-June 2021. Available at doi : https://doi.org/10.32628/IJSRST1218359 Journal URL : https://ijsrst.com/IJSRST1218359 